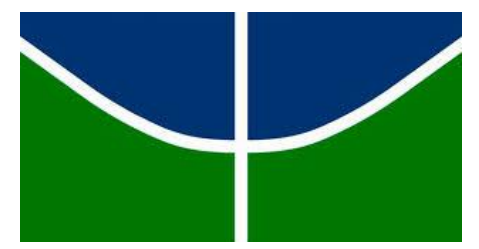

UNIVERSIDADE DE BRASÍLIA

\title{
DESCRIÇÕES MACRO E MICROESTRUTURAIS DO FÍGADO DE ZEBRAFISH (Danio rerio)
}

\section{LETÍCIA BATELLI DE OLIVEIRA}

DISSERTAÇÃO DE MESTRADO EM SAÚDE ANIMAL

BRASÍLIA-DF

DEZEMBRO/2015 


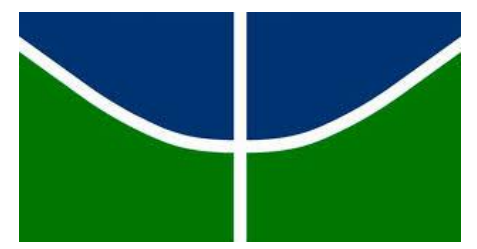

UNIVERSIDADE DE BRASÍLIA

\title{
DESCRIÇÕES MACRO E MICROESTRUTURAIS DO FÍGADO DE ZEBRAFISH (Danio rerio)
}

\author{
LETÍCIA BATELLI DE OLIVEIRA
}

\section{ORIENTADOR: EDUARDO MAURÍCIO MENDES DE LIMA}

DISSERTAÇÃO DE MESTRADO EM SAÚDE ANIMAL

PUBLICAÇÃO: 115/2015

BRASÍLIA-DF

DEZEMBRO/2015 
UNIVERSIDADE DE BRASÍLIA

DESCRIÇÕES MACRO E MICROESTRUTURAIS DO FIGGADO DE ZEBRAFISH (Danio rerio)

\section{LETÍCIA BATELLI DE OLIVEIRA}

DISSERTAÇ̃̃O

DE MESTRADO SUBMETIDA AO PROGRAMA DE PÓSGRADUAÇÃO EM SAÚDE ANIMAL, COMO PARTE DOS REQUISITOS NECESSÁRIOS Ȧ OBTENÇÃO DO GRAU DE MESTRE EM SAÚDE ANIMAL

APROVADA POR:

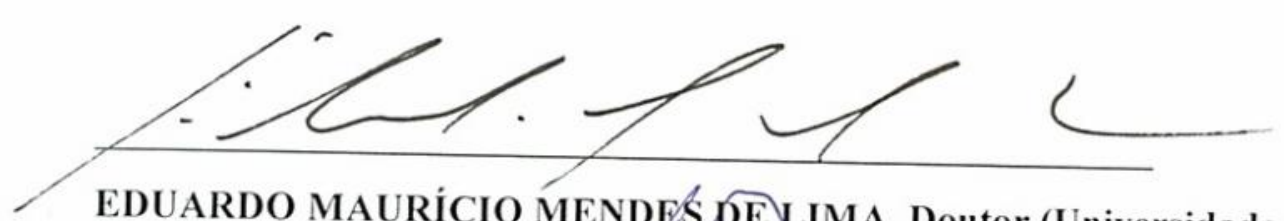

EDUARDO MAURICIO MENDES DE LIMA, Doutor (Universidade de Brasília)

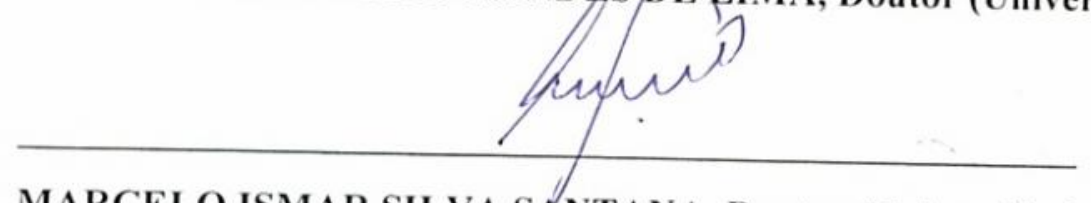

MARCELO ISMAR SILVA SANTANA, Doutor (Universidade de Brasília)

DANILA BARREIRO CAMPOS, Doutora (Universidade Federal da Paraiba)

BRASILIA-DF, 04 de DEZEMBRO de 2015 


\section{REFERÊNCIA BIBLIOGRÁFICA E CATALOGAÇÃO}

OLIVEIRA, L.B. Descrições macro e microestruturais do fígado de zebrafish (Danio rerio). Brasília: Faculdade de Agronomia e Medicina Veterinária, Universidade de Brasília, 2015, 18 p. Dissertação de Mestrado.

Documento formal, autorizando reprodução desta dissertação de mestrado para empréstimo ou comercialização, exclusivamente para fins acadêmicos, foi passado pelo autor à Universidade de Brasília e acha-se arquivado na Secretaria do Programa. O autor reserva para si os outros direitos autorais, de publicação. Nenhuma parte desta dissertação de mestrado pode ser reproduzida sem a autorização por escrito do autor. Citações são estimuladas, desde que citada a fonte.

\section{FICHA CATALOGRÁFICA}

Oliveira, Letícia Batelli

Descrições macro e microestruturais do fígado de zebrafish (Danio rerio). I Letícia Batelli de Oliveira; orientação de Eduardo Maurício Mendes de Lima - Brasília, 2015.18 p. : il.

Dissertação de Mestrado (M)- Universidade de Brasília/Faculdade de Agronomia e Medicina Veterinária, 2015.

1.Hepatócitos. 2.Peixe. 3. Densidade. 4. Macroscopia. 5.Glicogênio. I. Lima, E.M.M. II. Descrições macro e microestruturais do fígado de zebrafish (Danio rerio). 
"A maior utilidade da vida é usá-la em algo que dure mais do que ela." Willian James 


\section{ÍNDICE}

Página

RESUMO vii

$\begin{array}{lll}\text { ABSTRACT ix } & \text { ix }\end{array}$

INTRODUÇÃO 1

METODOLOGIA 2

RESULTADOS

$\begin{array}{ll}\text { DISCUSSÃO } & 12\end{array}$

$\begin{array}{ll}\text { CONCLUSÃO } & 16\end{array}$

$\begin{array}{ll}\text { REFERÊNCIAS } & 17\end{array}$ 


\section{Descrições Macro e Microestruturais do Fígado de Zebrafish (Danio rerio)}

\section{RESUMO}

O fígado é um órgão essencial e realiza várias atividades vitais, como metabolização, síntese e armazenamento. Este trabalho teve como objetivo descrever a macroscopia e microscopia do fígado do zebrafish e suas modificações temporais em treze semanas. Foram utilizados quarenta e seis (46) peixes da espécie Danio rerio, adultos, vinte e sete (27) fêmeas e dezenove (19) machos. Sete peixes foram eutanasiados para avaliação macroscópica e três peixes eutanasiados semanalmente durante treze semanas para avaliação microscópica. Realizou-se técnica histológica de rotina e as lâminas foram coradas com Hematoxilina/Eosina e Ácido Periódico de Schiff (PAS). Semanalmente, foram determinadas as densidades volumétricas $\left(\operatorname{Vv}_{(\mathrm{h})}\right)$ e numérica $\left(\mathrm{Nv}_{(\mathrm{h})}\right)$ dos hepatócitos e a intensidade de vacuolização. O fígado localizou-se na cavidade celomática ventralmente à bexiga natatória, apresentou coloração levemente amarronzado e estava dividido em três lobos hepáticos. Microscopicamente, era constituído por hepatócitos que formavam uma dupla camada celular ao redor de sinusóides. A coloração do citoplasma dos hepatócitos nos machos foi mais eosinofílica e nas fêmeas basofílica. Não foi observada a formação de tríades portais e células fagocitárias. A vesícula biliar apresentava epitélio de transição e os ductos biliares epitélio simples cúbico. As densidades volumétrica e numérica dos hepatócitos durante as treze semanas não apresentaram diferença estatística, mas a correlação entre esses parâmetros foi positiva. A vacuolização foi devido a presença de glicogênio. $O$ fígado de zebrafish possui particularidades macro e microestruturais e 
quantitativamente tem grande capacidade de adaptação do número e volume de hepatócitos em resposta às necessidades fisiológicas do animal naquele momento.

Palavras chave: hepatócitos, peixe, densidade, macroscopia, glicogênio. 


\title{
Macro- and microstructural descriptions of the zebrafish (Danio rerio) liver
}

\begin{abstract}
Liver is an essential organ and performs a number of vital activities such as metabolism, synthesis and storage. This research aimed to describe macroscopically and microscopically the liver of zebrafish and the liver temporal changes in thirteen weeks. We used forty six (46) fishes Danio rerio, adults, twenty seven (27) females and nineteen (19) males. Seven fishes were euthanized for macroscopic analyses and three fishes were euthanized weekly for thirteen weeks for microscopic analyses. It was conducted routine histological technique and the slides were stained with Hematoxylin/Eosin and periodic acid-Schiff (PAS). Weekly, it was determined volumetric $\left(\mathrm{Vv}_{(\mathrm{h})}\right)$ and numerical $\left(\mathrm{Nv}_{(\mathrm{h})}\right)$ densities of hepatocytes and intensity of vacuolization. The liver was located in the coelomic cavity ventrally to swim bladder, showed slightly brownish and was divided into three hepatic lobes. Microscopically, the liver consisted of hepatocytes arranged as a double cell layer around sinusoids. The staining of the cytoplasm of hepatocytes in males was more eosinophilic and basophilic than in females. Formation of portal triads and phagocytic cells were not found. The gallbladder had transitional epithelium and biliary ducts were composed by simple cubic epithelium. The volume and numerical density of hepatocytes during thirteen weeks showed no statistical difference, but the correlation between these parameters was positive. The vacuolization was due glycogen. The zebrafish liver has macro and microstructural features and quantitatively has great ability to adapt in volume and number of hepatocytes in response to the physiological needs.
\end{abstract}

Key words: hepatocytes, fish, density, macroscopy, glycogen. 


\section{INTRODUÇÃO}

O fígado dos peixes, assim como dos outros vertebrados, é a maior glândula do corpo, sendo responsável pela execução de muitas atividades vitais e pela fisiologia do animal. Está localizado na cavidade celomática e é basicamente formado por hepatócitos, células com alto potencial mitótico cuja função é de síntese, secreção, armazenamento, biotransformação e metabolismo (Costa et al. 2012).

De forma geral, os hepatócitos realizam a metabolização de substâncias endógenas e exógenas, produção de bile, que posteriormente é direcionada para a vesícula biliar, produção de proteínas essenciais do plasma e fatores de coagulação e armazenamento de substâncias como aminoácidos, lipídeos, glicogênio e ferro (Menke et al. 2011).

Além disso, outro importante papel do fígado é que ele serve como indicador do estado nutricional e fisiológico dos peixes (Bombonato et al. 2007). Devido suas funções de metabolização como bioindicador de poluição ambiental (Fredello et al. 2001) nesta espécie.

A partir da contextualização da relevância do fígado para manutenção da homeostase da espécie em questão. Foi objetivo do presente estudo a descrição macroscópica e microscópica do fígado destes animais avaliando ainda modificações temporais ao longo de 13 semanas. 


\section{METODOLOGIA}

O protocolo de experimentação foi aprovado pelo Comitê de Ética em Experimentação Animal da Universidade de Brasília sob protocolo n 127542/2013.

Foram utilizado peixes da espécie Danio rerio $(n=46)$, fêmeas $(n=27)$ e machos $(n=19)$, com idade entre 12 e 18 meses (adultos). Estes animais ficaram cerca de 60 dias em quarentena e aclimatização em um aquário de 19 litros, com densidade populacional de 3 peixes por litro. O experimento teve duração de 13 semanas, logo a idade dos animais no final do experimento estava entre 16 e 22 meses (adultos) correspondendo a aproximadamente $48 \%$ da expectativa de vida média destes animais em laboratório (Gilbert, Zerulla \& Tierney 2014).

Durante os períodos de adaptação e experimento, os animais foram submetidos a um ciclo de 14 horas luz e 10 horas escuro. Foram alimentados duas vezes ao dia com ração comercial em flocos (alcon Basic $^{\circledR}$ ) e criados em aquário com sistema de circulação fechado a temperatura de $26 \pm 2^{\circ} \mathrm{C}$ controlada por termostato $\left(\operatorname{Atman}{ }^{\circledR}\right)$.

A qualidade da água foi testada diariamente para $\mathrm{pH}$ (pH Tropical, LabconTest), semanalmente para amônia (Amônia Tóxica, LabconTest) e mensalmente para oxigênio dissolvido $\left(\mathrm{O}_{2}\right.$ Dissolvido, LabconTest), obtendo-se em torno de 6,8-7,0, 00,001 mg/L e 6-8 mg/L respectivamente. A temperatura também foi aferida diariamente com termômetro Glass Thermometer (Aquadene ${ }^{\circledR}$ ).

A eutanásia dos peixes foi realizada imergindo-os em solução aquosa de 3-etilaminobenzoato $0,2 \%$ (Sigma-Aldrich Chemistry), seguida de imersão em água gelada (4ํㅡ) por 15 minutos (Gupta \& Mullins 2010). 
Para avaliação macroscópica, sete peixes escolhidos aleatoriamente foram eutanasiados e a necropsia foi realizada conforme as técnicas descritas para dissecação de zebrafish (Gupta \& Mullins 2010) com auxílio de microscópio óptico (BX51 Olympus ${ }^{\circledR}$ ) na objetiva de 4x. As imagens do fígado foram capturadas (BMP, 24bit color, 2048x1536 pixels) com microscópio acoplado à câmera fotográfica (Moticam 3, Motic $^{\circledR}$ ) e com programa de captura e análise de imagens (ProgRes ${ }^{\circledR}$ Capture Pro 2.5).

Para avaliação microscópica, três peixes foram eutanasiados semanalmente. Fixados inteiros em solução aquosa de Dietrich por 24 horas, removendo-se somente o opérculo e a nadadeira peitoral esquerda e a caudal, conforme o recomendado pelo Zebrafish International Resource Center (ZIRC). Utilizou-se a técnica histológica de rotina, com desidratação crescente em álcool etílico, diafanização em xilol, impregnação e inclusão em parafina. Os blocos foram cortados no plano sagital na espessura de $3 \mu \mathrm{m}$ com uso do micrótomo manual (Leica RM 2125RT). De cada fragmento foram preparadas três lâminas com pelo menos dois cortes em cada uma, que foram coradas com Hematoxilina/Eosina para análise histológica do fígado, verificando a organização do parênquima hepático, sua topografia, conformação das células e os componentes do órgão. Além disso, também foi realizado coloração pelo método Ácido Periódico de Schiff (PAS).

Foram capturadas nove imagens de campos aleatórios por semana com o auxílio de um microscópio óptico (Leica DM500 ${ }^{\circledR}$ ) acoplado à câmera fotográfica (Leica ICC50 $\mathrm{HD}^{\circledR}$ ) e ao programa de captura e análise de imagens (Leica ${ }^{\circledR}$ LAS EZ 2.0). Foram determinadas a densidade volumétrica dos hepatócitos $\left(\mathrm{Vv}_{(\mathrm{h})}\right)$ e a densidade 
numérica dos hepatócitos $\left(\mathrm{Nv}_{(\mathrm{h})}\right)$. Foi avaliado a intensidade da vacuolização por semana, sendo classificada por sistema de cruzes em uma escala de um (+) a três $(+++)$, onde uma cruz $(+)$ representa menor intensidade de vacuolização e três $(+++)$ maior (Li et al. 2003).

As densidades volumétricas foram determinadas por contagem dos pontos que tocavam o núcleo dos hepatócitos. A densidade numérica de hepatócitos foi obtida a partir da quantidade de núcleos vistos por área (Marcos, Monteiro \& Rocha 2012). Para quantificar as densidades numéricas e volumétricas utilizou-se o software de análise estereológica STEPanizer ${ }^{\circledR}$ (http://stepnizer.com/).

Os dados obtidos entre as semanas foram submetidos inicialmente à estatística descritiva para a obtenção da média e erro-padrão da média, seguida pela aplicação do teste de normalidade de Kolmogorov-Smirnov, análise de variância one-way ANOVA e correlação de Pearson ou Spearman, de acordo com o resultado obtido no teste de normalidade. Em todos os testes foi utilizado o programa GraphPad Prism ${ }^{\circledR} 6$, sendo considerado significativo $p \leq 0,05$. 


\section{RESULTADOS}

\section{Descrição macroscópica}

O fígado esteve disposto na cavidade celomática como órgão parenquimatoso, de aspecto denso, homogêneo, levemente amarronzado e bastante vascularizado; estando localizado na região medial do corpo (Figura 1A). Ventralmente ao fígado encontrava-se a parede celomática ventral ou, conforme sua distensão, o intestino. Este também situava-se medialmente ao fígado juntamente com o pâncreas (Figura 1B). Ainda na porção ventral do fígado observou-se uma estrutura em forma de saculação, ovalada e de coloração esverdeada representando a vesícula biliar (Figura 1C). Dorsalmente estava a bexiga natatória e, caudalmente, o órgão reprodutor (ovário ou testículo). Cranialmente ao fígado havia o rim, na porção mais dorsal, e o seio venoso, ventralmente. De forma geral, o fígado apresentou-se sendo formado por três lobos hepáticos, assimétricos, dois laterais (direito e esquerdo), sendo o esquerdo de maior proporção, e um transversal, de menor tamanho que uniu os lobos laterais (Figura 1D). 

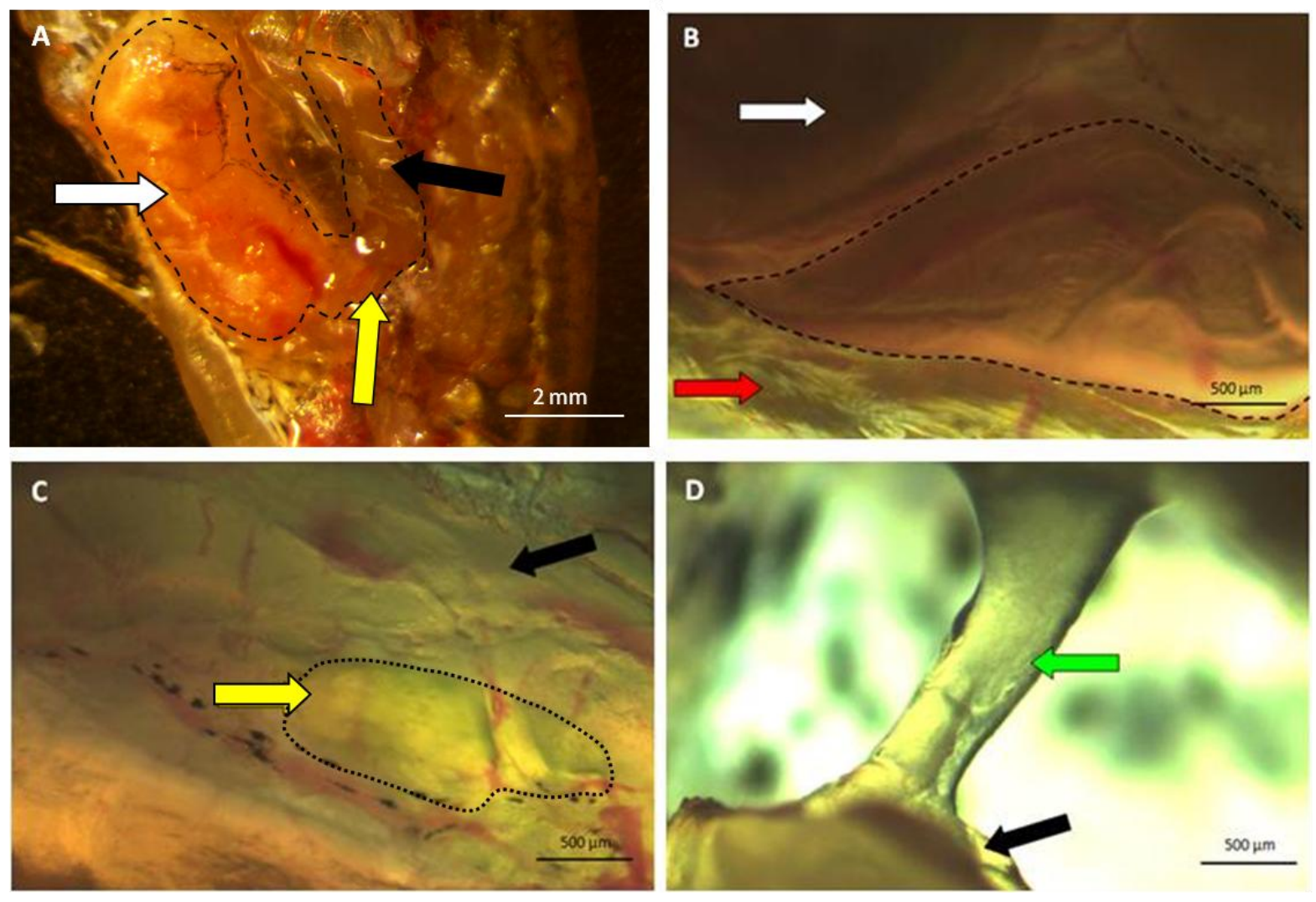

Figura 1. Fígado de zebrafish. (A) Fígado (tracejado) com lobo hepático esquerdo (seta branca), lobo transversal (seta amarela) e lobo direito (seta preta). (B) Intestino (seta branca) e parede celomática ventral (seta vermelha). (C) Lobo esquerdo do fígado (seta preta) com vesícula biliar (seta amarela e pontilhado). (D) Lobo transversal (seta verde).

\section{Descrição histológica}

Ao corte histológico, o fígado localizava-se na cavidade celomática com os demais órgãos (Figura 2A), sendo formado basicamente por hepatócitos dispostos como uma dupla camada celular ao redor de sinusóides (Figura 2B). Os hepatócitos eram poliédricos, com bordos distintos, amplo citoplasma com diferentes graus de vacuolização. A coloração do citoplasma diferiu entre os sexos, sendo que nos machos foi mais eosinofílico (Figura 2C) e nas fêmeas basofílico (Figura 2D). 
O núcleo dos hepatócitos era único, arredondado, basofílico e geralmente central ou levemente periférico. Nos casos em que a vacuolização era mais acentuada, o núcleo apresentava-se rebatido para a periferia (Figura 2G).

Não havia a formação de uma tríade portal e nem a presença de células fagocitárias.

A vesícula biliar apresentava-se como uma estrutura oca, com epitélio de transição, enquanto os ductos biliares demonstravam epitélio simples cúbico (Figura 2E e 2F).

Os vasos sanguíneos do fígado eram constituídos por epitélio simples pavimentoso, assim como o visualizado na cápsula hepática que reveste o órgão (Figura $2 \mathrm{G}$ e 2H). 

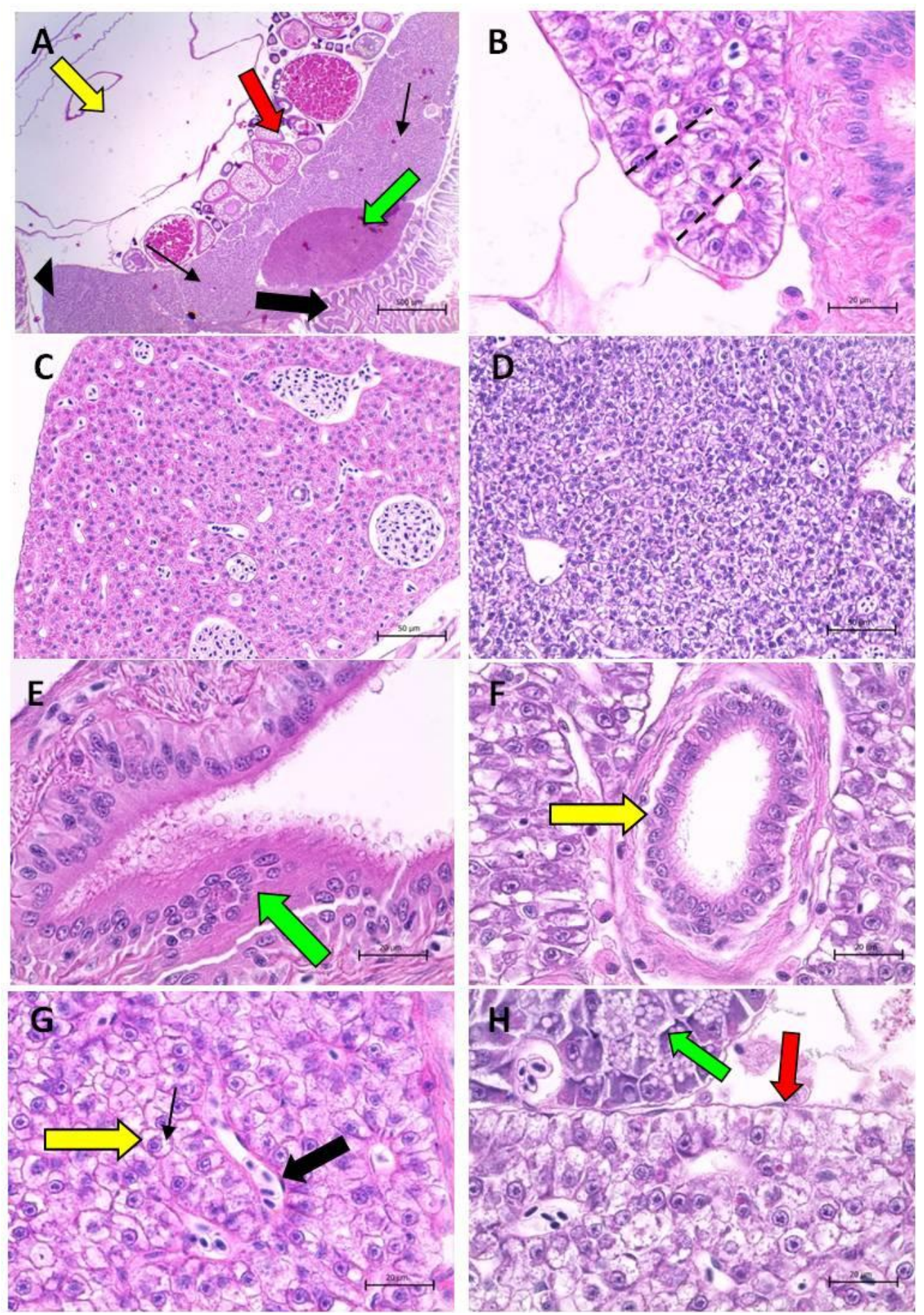

Figura 2. Fígado de zebrafish. Coloração em HE. (A) Bexiga natatória (seta grossa amarela), ovário (seta grossa vermelha), fígado (setas fina), pâncreas (seta grossa verde), intestino (seta grossa preta) e rim (cabeça da seta), 4aㅗ semana. (B) Parede dupla dos hepatócitos ao redor dos sinusóides (tracejado), 
6ª semana. (C) Fígado de coloração eosinofílica do macho, 3aㅗ semana. (D) Fígado de coloração basofílica da fêmea, 3ํㅗㄹ semana. (E) Vesícula biliar (seta grossa verde), 6ª semana. (F) Epitélio cúbico do ducto biliar (seta grossa amarela), 4⿳亠丷厂 semana. (G) Epitélio pavimentoso vaso sanguíneo (seta grossa preta) e hepatócito com núcleo central (seta amarela) e vacuolização (seta fina), 6aㅗ semana. (H) Epitélio da cápsula de revestimento (seta grossa vermelha) com pâncreas (seta grossa verde), $3^{\text {a }}$ semana.

\section{Análise Temporal}

A densidade volumétrica e numérica dos hepatócitos e a intensidade de vacuolização ao longo das 13 semanas estiveram representadas na figura e tabela abaixo (Figura 3 e Tabela 1). Os testes de correlação entre os parâmetros avaliados foram representados no quadro 1.
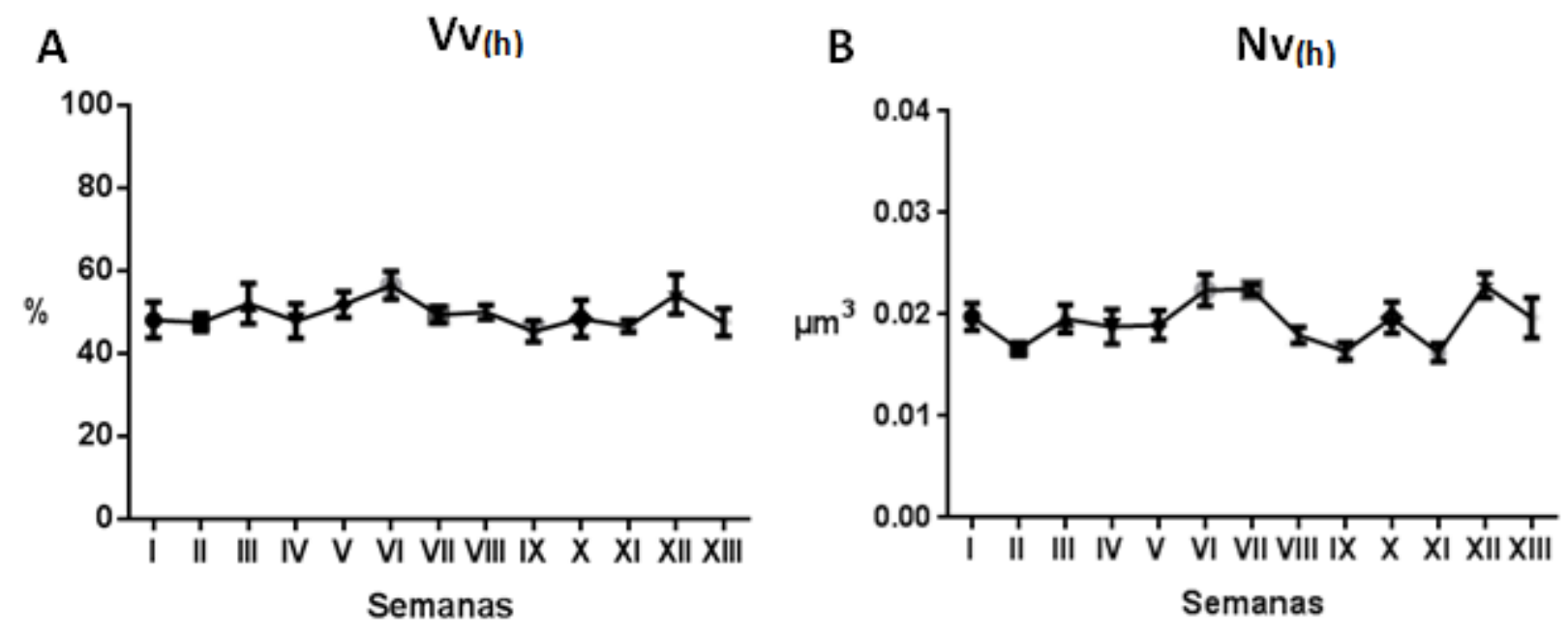

Figura 3. Representações gráficas da média \pm erro padrão da média das densidades em 13 semanas. (A) Densidade de volume dos hepatócitos $-\mathrm{Vv}_{(\mathrm{h})}$. $(B)$ Densidade numérica dos hepatócitos $-\mathrm{Nv}_{(\mathrm{h})}$. Sem diferença estatística $(p \geq 0,05)$ entre as semanas. One-way ANOVA. 
Tabela 1. Variação da intensidade de vacuolização o longo das 13 semanas.

\begin{tabular}{cccccccccccccc}
\hline Semanas & I & II & III & IV & V & VI & VII & VIII & IX & X & XI & XII & XIII \\
\hline Vacuolização & + & +++ & ++ & ++ & +++ & ++ & +++ & & & & & & \\
& & & & & & & & & & & & & \\
\hline
\end{tabular}

Legenda: (+) discreto; (++) moderado; (+++) acentuado.

A coloração PAS foi positiva (Figura 4A e 4B), indicando que as vacuolização visualizadas eram de degeneração glicogênica.
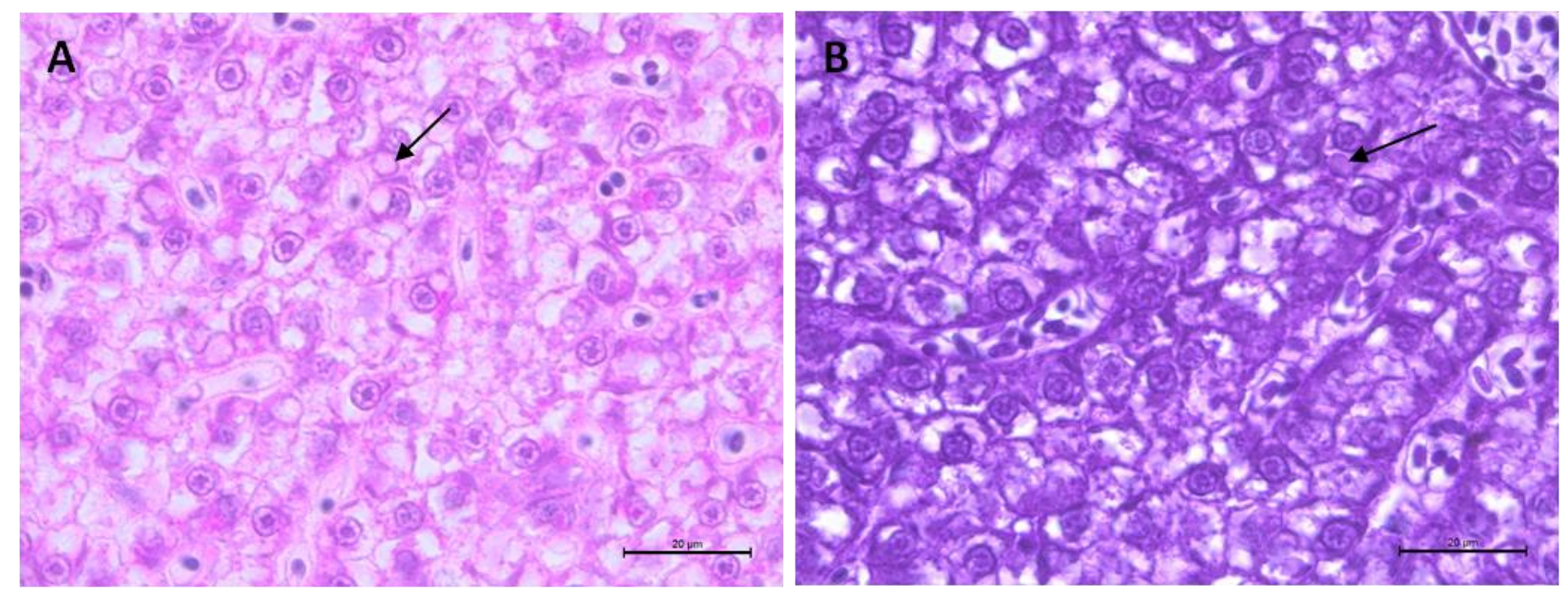

Figura 4. Fígado de zebrafish da 10ª semana. (A) Vacuolização (seta) intensidade (++) em HE. (B) Vacuolização (seta) intensidade (++) positivo no PAS.

Quadro 1. Correlação de Pearson ou Spearman ( $r)$ das densidades de volume $\left(\mathrm{VV}_{(\mathrm{h})}\right)$ e numérica dos hepatócitos $\left(\mathrm{Nv}_{(\mathrm{h})}\right)$ durante as treze semanas. Valores de r estatisticamente significantes $\left({ }^{*}\right)(p \leq 0,05)$.

\begin{tabular}{|c|c|c|c|c|c|c|c|c|c|c|c|c|c|}
\cline { 2 - 12 } \multicolumn{1}{c|}{} & I & II & III & IV & V & VI & VII & VIII & IX & X & XI & XII & XIII \\
\hline $\begin{array}{c}\text { Valor de r } \\
\text { Vv(h) X Nv(h) }\end{array}$ & $0,86^{*}$ & 0,04 & $0,94^{*}$ & $0,93^{*}$ & $0,69^{*}$ & $0,69^{\star}$ & 0,38 & $0,75^{\star}$ & $0,66^{*}$ & $0,75^{*}$ & 0,06 & 0,61 & $0,88^{*}$ \\
\hline
\end{tabular}

A maioria das semanas apresentou uma correlação significativa positiva de moderada a forte entre as densidades volumétrica e numérica dos hepatócitos. 
Somente as semanas II e XI mostraram que as variáveis foram independentes, não havendo relação, comprovada pela diferença estatística. 


\section{DISCUSSÃO}

\section{Macroscopia e histologia}

Os achados macroscópicos e microscópicos observados no fígado do zebrafish foram similares aos encontradas em outros teleósteos (Bombonato et al. 2007, Gupta \& Mullins 2010, Costa et al. 2012). Sua disposição na porção medial da cavidade celomática, assim como seu tamanho e formato, ocorreram devido a uma adaptação ao espaço utilizado por outros órgãos durante o desenvolvimento embrionário (Costa et al. 2012). Além disso, a cor amarronzada visualizada foi consequência da rica vascularização do órgão.

Diferente dos mamíferos, os hepatócitos do zebrafish não formavam lóbulos e não apresentaram células fagocitárias no fígado (Menke et al. 2011). Além disso, estiveram organizados formando uma dupla camada de células circundando um capilar sinusóide. Este arranjo também foi observado em peixes Oreochromis niloticus e Leporinus macrocephalus, sendo que nesta espécie, esta organização foi denominada de "muralha dupla" (Vicentini et al. 2005, Bombonato et al. 2007). A ausência de tríade e células fagocitárias sugeriram que o fígado desta espécie apresentou-se menos evoluído quando comparado com o dos mamíferos. O arranjo de muralha dupla sugere um mecanismos para facilitação da nutrição dos hepatócitos e eliminação dos seus produtos para a corrente sanguínea.

Uma característica espécie-específica do zebrafish foi a capacidade de se diferenciar os sexos pela coloração do citoplasma dos hepatócitos, quando fêmeas apresentaram citoplasma basofílico e os machos eosinofílico. Essa coloração basofílica 
visualizada nas fêmeas foi decorrente da produção de vitelogenina (Menke et al. 2011). A vitelogenina foi caracterizada como uma lipo-fosfo-glicoproteína produzida no fígado das fêmeas pelos hepatócitos, por estímulo do estradiol. Sendo liberada na corrente sanguínea e captada pelos ovócitos, originando as proteínas da gema do ovo que manterão o embrião (Pankhurst \& Munday 2011). Portanto, o presente estudo leva a crer que as fêmeas do experimento apresentaram quantidades mais elevadas de vitelogenina nos hepatócitos em relação aos machos. Provavelmente isto foi observado devido a vitelogênese que ocorreu antes do período de reprodução, visto que a amostra apresentava idade homogênea.

Outra particularidade do zebrafish observada foi o epitélio de transição da vesícula biliar. Este tipo de epitélio também foi visualizado em outros zebrafish (Menke et al. 2011). O epitélio de transição possui grande capacidade de distensão e distorção, permitindo que o órgão aumente e diminua de volume sem o extravasamento do conteúdo. Já no prismático cada célula possui uma função, como a de absorção de água e troca de íons para concentração da bile. Logo, foi possível entender que a vesícula biliar desta espécie tem somente a função de armazenamento e não de concentração da bile, entendendo-se que a bile é excretada da forma como foi produzida pelos hepatócitos.

\section{Análise Temporal}

A densidade volumétrica e numérica dos hepatócitos ao longo das 13 semanas não apresentou diferenças significativas. De outra forma foi observada correlação positiva de moderada a forte entre elas, significantes em sua maior parte. Este achado 
indicou que fatores que interferiram na densidade volumétrica também agiram na densidade numérica. $\mathrm{O}$ aumento da demanda de proteínas para produção de vitelogenina e outros precursores hepáticos, principalmente na época de reprodução, resultou na proliferação de retículo endoplasmático rugoso e dictiossoma (Rocha et al. 2010). Em Salmo trutta fario foi observada a proliferação de hepatócitos na época reprodutiva e declínio do número dessas células posteriormente ocasionado por um ciclo alternado de mitose e apoptose no fígado. Essas alterações foram encontradas, tanto em machos quanto nas fêmeas, sendo mais intensas em fêmeas do que em machos (Rocha et al. 2009). Portanto, no presente trabalho, sugere-se que a mudança de volume dos hepatócitos do zebrafish ocorreu devido a proliferação de organelas e a variação no número por mitose e apoptose de hepatócitos de acordo com a demanda da produção, principalmente de proteína. Logo, a demanda metabólica apresentou uma certa tendência com a massa do fígado e consequentemente com as densidades dos hepatócitos.

As diferentes intensidades de vacuolização visualizadas nos animais deste experimento foram positivas na histoquímica PAS, indicando degeneração glicogênica. Em um estudo em Oreochromis niloticus foi observado hepatócitos demonstrando quantidades relativamente baixas de organelas, sugerindo portanto uma baixa atividade na secreção das proteínas em relação aos mamíferos e justificando seu acúmulo intracelular (Vicentini et al. 2005). Trabalhos observaram que a quantidade de glicogênio esteve relacionada com o estado nutricional, sendo que animais bem alimentados e saudáveis apresentaram maior teor de glicogênio quando comparados com fígados alterados (Rocha et al. 2010). Portanto, no presente trabalho, a difusa 
presença de glicogênio intracitoplasmático, mesmo que com teores distintos, indicou que os zebrafish estavam em bom estado nutricional e saudáveis ao longo de todas semanas. Seu acúmulo também levou a crer que esta espécie possui uma baixa quantidade de organelas que auxiliariam em sua excreção.

A mesma variabilidade do teor de glicogênio foi visualizada em Salmo trutta fario, com alto teor principalmente no período reprodutivo, pois nesta época houve a grande demanda de energia para produção de proteínas e síntese de lipídios (Rocha et al. 2010). Em suma, foi possível entender que muitos fatores interferiram na quantidade de glicogênio, pois este teor esteve ligado à produção de energia, sugerindo que a demanda da mesma, vai depender da necessidade fisiológica dos peixes, em especial ao longo do tempo avaliado. 


\section{CONCLUSÃO}

As características morfológicas visualizadas no fígado do zebrafish foram semelhantes às encontradas em outros teleósteos. Diferindo na sua organização histológica em dupla camada circundando sinusóides e ausência de tríades hepáticas. A histoquímica permitiu, nesta espécie, diferenciar o fígado entre os gêneros, provavelmente devido a presença de vitelogenina em fêmeas. As densidades volumétrica e numérica dos hepatócitos durante 13 semanas não apresentaram diferenças significativas. Porém a correlação entre esses parâmetros quantitativos foi significativa e positiva na maioria das semanas, indicando que o fígado possui grande plasticidade quanto às alterações funcionais e estruturais, adaptando-se em volume e número conforme as suas necessidades fisiológicas. 


\section{REFERÊNCIAS}

BOMBONATO, M.T.S.; ROCHEL, S.S.; VINCENTINI, C.A.; VICENTINI, I.B.F. Estudo morfológico do tecido hepático de Leporinus macrocephalus. Acta Scientiarum Biological Sciences, 29(1), 81-85, 2007.

COSTA, G.M.; ORTIS, R.C.; LIMA, M.G.; CASALS, J.B.; LIMA, A.R.; JR KFOURY, J.R. Estrutura morfológica do fígado de tambaqui Colossoma macropomum (Cuvier, 1818). Pesquisa Veterinária Brasileira, 32(9), 947-950, 2012.

GILBERT, M.J.; ZERULLA, T.C.; TIERNEY, K.B. Zebrafish (Danio rerio) as a model for the study of aging and exercise: Physical ability and trainability decrease with age. Experimental Gerontology, 50, $106-113,2014$.

GUPTA, T.; MULLINS, M.C. Dissection of Organs from the Adult Zebrafish. Journal of Visualized Experiments, 37, e.1717, 2010.

FREDELLO, J.P.; RAQBI, A.; MATTEI, X.; VIALE, D.; MARCHAND, B. Quantification of macrophage aggregates in the liver of Mugil cephalus. Journal of Submicroscopy Cytology and Pathology, 33, 473-473, 2001.

LI, X.; ELWELL, M.R.; RYAN, A.M.; OCHOA, R. Morphogenesis of postmortem hepatocyte vacuolation and liver weight increases in Sprague-Dawley rats. Toxicologic Pathology, 31(6), 682-688, 2003.

MARCOS, R.; MONTEIRO, R.A.F.; ROCHA, E. The use of design-based stereology to evaluate volumes and numbers in the liver: a review with practical guidelines. Journal of Anatomy, 220(4), 303-317, 2012.

MENKE, A.L.; SPITSBERGEN, J.M.; WOLTERBEEK, A.P.; WOUTERSEN, R.A. Normal anatomy and histology of the adult zebrafish. Toxicologic Pathology, 39(5), 759-775, 2011.

PANKHURST, N.W.; MUNDAY, P.L. Effects of climate change on fish reproduction and early life history stages. Marine and Freshwater Research, 62(9), 1015-1026, 2011. 
ROCHA, E.; ROCHA, M.J.; GALANTE, M.H.; SILVA, M.W.; MONTEIRO, R.A.F. The hepatocytes of the brown trout (Salmo trutta fario): A stereological study of their number and size along the breeding cycle. Ichthyological Research, 56, 43-54, 2009.

ROCHA, E.; ROCHA, M.J.; LOBO-DA-CUNHA, A.; GALANTE, M.H.; MONTEIRO, R.A. The hepatocytes of the brown trout (Salmo trutta fario): a stereological study of some cytoplasmic components with the breeding cycle. Microscopy Research and Technique, 73, 766-78, 2010.

VICENTINI, C.A.; FRANCESCHINI-VICENTINI, I.B.; BOMBONATO, M.T.S.; BERTOLUCCI, B.; LIMA S.G.; SANTOS, A.S. Morphological study of the liver in the teleost Oreochromis niloticus. International Journal of Morphology, 23(3), 211-16, 2005. 